\title{
Catha edulis chewing effects on treatment of paranoid schizophrenic patients
}

\author{
This article was published in the following Dove Press journal: \\ Neuropsychiatric Disease and Treatment \\ 15 April 2015 \\ Number of times this article has been viewed
}

\author{
Mohamed-I Kotb El-Sayed \\ Hatem-K Amin \\ Department of Biochemistry \\ and Molecular Biology, Faculty \\ of Pharmacy, Helwan University, \\ Ain Helwan, Helwan, Cairo, Egypt
}

Background: The current study's aim is to evaluate the possible interaction effects of khat chewing on treatment of paranoid schizophrenic patients.

Patients and methods: In the study group, 42 male subjects suffered from paranoid schizophrenia and were classified according to their khat chewing habits into two subgroups: either khat-chewer subgroup (SKc; $\mathrm{n}=21 ; r=11, h=10$ ) or non-khat-chewer subgroup (SNKc; $\mathrm{n}=21, r=11, h=10$ ). Each subgroup was further subdivided according to type of treatment into $\mathrm{r}$ (risperidone) and $\mathrm{h}$ (haloperidol). Healthy male subjects (37) were subdivided into healthy khat-chewer as positive controls $(\mathrm{HKc}, \mathrm{n}=17)$ and healthy non-khat-chewer as negative controls (HNKc, n=20). Plasma dopamine, 3,4-dihydroxyphenylacetic acid (DOPAC), homovanillic acid, 5-hydroxytryptamine (serotonin), 5-hydroxyindoleacetic acid, epinephrine, and norepinephrine were estimated.

Results: ANOVA and post hoc analysis showed that dopamine was illustrating significant elevation in all khat chewing groups. DOPAC was illustrating significant decrease in all khat chewing groups with an interesting outcome showing significant increase in DOPAC in SNKcr group due to risperidone effect. Homovanillic acid, serotonin, hydroxyindoleacetic acid, and norepinephrine were illustrating significant elevations in all khat chewing groups. Epinephrine was illustrating significant elevation in all chewers than non-chewers groups. Unexpected significant decrease in epinephrine in the SNKcr group indicated that risperidone drug is decreasing epinephrine through indirect mechanism involving calcium.

Conclusion: Khat chewing in schizophrenic patients is contraindicated because it aggravates the disease symptoms, attenuates all used treatment medications, and deteriorates all biochemical markers of the patients.

Keywords: epinephrine, norepinephrine, dopamine, serotonin, schizophrenia, khat

\section{Introduction}

Schizophrenia is a severe neuropsychiatric mental disorder caused by inherent dysfunction of the brain, occurs in about $1 \%$ of the population, and is characterized by hallucinations, delusions, and thinking or speech disturbances. Schizophrenia presents positive symptoms such as auditory hallucination, mood abnormality, lack of insight into the illness delusions, and initial vagueness in speech, whereas the negative symptoms present emotional apathy, lack of drive, and social withdrawal. ${ }^{1}$

Functional and structural disconnectivities are among the most reproducible neurophysiological abnormalities associated with schizophrenia and refer to macroscopic neuroanatomical dynamics and are mainly measured by diffusion-tensor imaging, tractography, volumetric magnetic resonance imaging, and magnetization-transfer imaging. ${ }^{2}$

Neuroinflammatory mechanisms implicated in schizophrenia include glial (astroglial loss and activation, microglial activation, and priming), immunologic (cytokines, 
chemokines, and prostaglandins), and oxidative (reactive oxygen and nitrogen species) aberrations. These mechanisms are thought to result in glutamatergic (hypofunction) and dopaminergic (limbic hyperfunction, frontal hypofunction) dysregulations. ${ }^{3}$

Schizophrenia can be genetic, although in many cases of identical twins, only one sibling developed schizophrenia. Another postulation is the dopamine (DA) receptor's abnormality, mainly D2 receptors. Other factors could implicate in schizophrenia such as toxins, family environment, migration, and socioeconomic factors. ${ }^{1}$

Khat leaves (Catha edulis Forsk) has a stimulant effect and comes from West Asia and countries bordering the Red Sea in east coast Africa. Khat is traditionally consumed by keeping the slowly chewed leaves in the side of the cheek, releasing the Khat active constituents, and swallowing with saliva., ${ }^{4,5}$

High consumption of Khat resulted in a state resembling paranoid schizophrenia or maniac behavior. A short-lived schizophrenic from psychotic illness and mania due to excessive khat chewing was documented presenting psychotic paranoid delusions and manic-like psychosis. ${ }^{6-10}$

Khat contains cathinone and cathine, which have sympathomimetic effects mediated through cathinone-induced catecholamine secretion by releasing catecholamines from presynaptic storage sites, and inhibit catecholamines reuptake and also monoamine oxidase enzyme (MAO). These amines include DA and serotonin. ${ }^{11}$ Khat may have also MAO inhibiting action. ${ }^{12}$

DA or $\beta$-(3,4-dihydroxyphenyl)ethylamine is an endogenous neurotransmitter catecholamine transmitting signals between neurons that are separated by a synaptic cleft. ${ }^{13}$ Serotonin (5-hydroxytryptamine [5-HT]) is an indolamine monoamine neurotransmitter in the central nervous system (CNS), mainly in the basal ganglia and limbic system. ${ }^{14,15}$

Khat psychostimulant activity is mediated through release of DA and 5-HT. ${ }^{16}$ The metabolism of serotonin is primarily done by MAO. The principle metabolite of serotonin is hydroxyindoleacetic acid (HIAA). ${ }^{17}$

Intermittent oral administration of $C$. edulis extract (200 mg/kg) induces DOPAC significant reduction with increment of urinary catecholamine (HVA) indicating amine oxidase activity inhibition. ${ }^{4,18,19}$

Khat effect is due to DA release rather than $5-\mathrm{HT}$ release. ${ }^{16,20}$ Cathinone (beta-keto analog of amphetamine) is the main psychoactive alkaloid of fresh khat leaves and has indirect sympathomimetic mechanism through modulating the release of catecholamines, mainly DA from storage sites in the synaptic terminal, and indirectly affects electrolyte balance by increasing copper and calcium and decreasing zinc plasma concentrations. Cathinone (-) isomer is approximately three times more potent than $(+)$ isomer at DA terminals in the CNS. ${ }^{12,20-23}$

It was reported that cathinone may act on noradrenaline transporters. ${ }^{24}$ Schizophrenia is treated by neuroleptic drugs, which have an antipsychotic effect; haloperidol drug binds preferentially to $\mathrm{D} 2$ and Alpha 1 receptors at low dose (ED50 $=0.13 \mathrm{mg} / \mathrm{kg}$ and $0.42 \mathrm{mg} / \mathrm{kg}$, respectively) and 5 -HT2 receptors at a higher dose $(\mathrm{ED} 50=2.6 \mathrm{mg} / \mathrm{kg})$ with pronounced DA antagonism. Haloperidol, a non-selective DA antagonist, was found to reduce cathinone-induced biting and licking movements. ${ }^{25}$ Risperidone is a second-generation antipsychotic with more pronounced serotonin antagonism than DA antagonism. ${ }^{26}$

This study was aimed to evaluate the interference of Khat chewing with antipsychotic medications by assaying DA, serotonin, epinephrine, norepinephrine, and their related metabolites.

\section{Patients and methods \\ Ethical consideration}

Written consent was taken from all participants as a routine admission protocol. As the hospital is a mental and psychiatric health hospital (Al-Amal Hospital) in Sana'a, Yemen, it is a charge-free governmental hospital, and all patients were informed that their diagnosis and biological samples taking during diagnosis will be recorded and could be used anonymously for education and research purposes.

The research protocol followed all the ethical regulations stated by the scientific research ethical committee in the university. Protocol, consent format, recorded information, and sampling procedures were approved by the committee. The university and the hospital ethical regulations prohibit disclosing names and personal information of any patients without legislative procedure or applying any invasive protocol was not needed for the diagnosis such as tissue biopsy.

All our blood samples were collected during regular and routine diagnosis procedure of patients without using any invasive protocols. The authors are confirmed that they did not administer khat in purpose for the patients. Khat groups were classified by asking the patients during patient history recording as khat is a common traditional medicine and being used routinely in a widespread manner in Yemen.

\section{Study design}

The current study was carried out as a case-control study. In all, 79 Yemeni male subjects were recruited (aged 
$39.64 \pm 0.44$ years, body mass index averaged $8 \pm 1.2 \mathrm{~kg} / \mathrm{m}^{2}$, and were nonsmokers), out of which 42 subjects suffered from late-onset paranoid schizophrenia. They were examined and treated during temporary remission in the psychiatric department and were classified according to their khat chewing habits into two main subgroups: either khat-chewer subgroup (SKc; $\mathrm{n}=21, r=11, h=10$ ), patients chewed khat during treatment (when they were discharged for holidays), or non-khatchewer subgroup (SNKc; $\mathrm{n}=21, r=11, h=10$ ). Each subgroup further subdivided according to type of treatment into $r$ (risperidone) and $\mathrm{h}$ (haloperidol). The daily doses of risperidone and haloperidol were $5 \mathrm{mg}$ and $10 \mathrm{mg}$, respectively.

Healthy subjects who chewed khat and were not suffering from paranoid schizophrenia were taken as positive controls (HKc, $n=17$ ). Healthy subjects who did not chew khat and were not suffering from paranoid schizophrenia were taken as negative controls ( $\mathrm{HNKc}, \mathrm{n}=20)$.

All subjects (in groups HKc or SKc) were demonstrating khat chewing habits, determined as daily abuse with duration of 4-8 hours, and khat chewing habit was highly comparable within the patient groups in quantity (average 100-120 g).

Patients' inclusion criteria considered age, sex, onset of disease, previous readmission to hospital, past history of mental illness, family history of mental illness, and date of admission of each patient, while the exclusion criteria excluded dementia or mental retardation diagnosis, any intermittent therapy (on/off), and any patient exposed to severe drug side effects, shifted from one drug to another, or administered any concomitant psychotropic medications.

\section{Sociodemographic and clinical characteristics}

On admission, all patients underwent a routine clinical interview with specialist psychiatrist to register psychotic symptoms using the rating instrument that assesses even different symptoms of schizophrenia instrument; positive and negative syndrome scale (PANSS) ${ }^{27}$ comprises three components: positive $(\mathrm{P})$, negative $(\mathrm{N})$, and cognitive or general psychopathology $(\mathrm{G})$. Positive syndrome is composed of symptoms such as delusions, hallucinations, and disorganized thinking. Negative syndrome is characterized by deficits in cognitive, affective, and social functions, including blunting affect and passive withdrawal. General psychopathology is composed of many deficits in cognition such as disorientation, poor attention, lack of insight, and active social avoidance. Positive and negative subscales each contain seven items (P1-P7, N1-N7); General psychopathology subscale contains 16 items with the major emphasis on cognition (G1-G16). Diagnosis at discharge was given according to the $I C D-10$ classification of mental and behavioral disorders. ${ }^{28}$

\section{Sample collection}

Venous blood samples were collected 2 hours after lunch in the HNKc group, 1 hour after treatment in the SNKc group, 1 hour after treatment and starting of continued khat chewing in SKc, and 1 hour after starting of continued khat chewing in HKc (they chewed the khat outside the hospital before coming to outpatient psychiatric department and then underwent blood drawing) using vacutainer. Blood samples were collected on EDTA tubes and immediately centrifuged at $3,500 \times g$ for 10 minutes, and separated plasma was divided into six separated aliquots in Eppendorf (micro centrifuge) tubes and stored at $-70^{\circ} \mathrm{C}$ for later analysis of DA (Cat No CEA851Ge), homovanillic acid (HVA) (Cat No CED717Ge), 5-hydroxytryptamine (serotonin) (Cat No CEA808Ge), 5-HIAA (Cat No CEB005Ge), epinephrine (Cat No CEA858Ge), and norepinephrine (Cat No CEA907Ge) using ELISA kits from Cloud-Clone Corp Company (Houston, TX, USA) and following the manufacturer instructions, while 3,4-dihydroxyphenylacetic acid (DOPAC) was measured using microdialysis-HPLC as described by Dethy et al. ${ }^{29}$

\section{Data analysis}

Data were collected and analyzed using SPSS version 15 (SPSS Inc., Chicago, IL, USA). One-way ANOVA was used to assess the difference between frequencies (the associations between khat chewing and paranoid schizophrenia). Tukey's post hoc test was used to test the difference between subgroup means, and $F$ value test tested the multivariate effect of investigated subjects using multivariate Pillai's trace, Wilks' lambda, Hotelling trace, and Roy's largest root tests. These tests are based on the linearly independent pairwise comparisons among the estimated marginal means. Pearson's chi-squared test was used to test the significant differences between PANSS scores from study baseline and after 6 weeks and 12 weeks duration; Phi and Cramer's V were used as symmetric measures to evaluate the chi-square correlation strength. Observed difference was considered to be significant at $P<0.05$.

\section{Results}

All analyzed data in the ANOVA table (Table 1) and multivariate tests table (Table 2 ) are showing highly significant correlations between groups and within groups. 
Table I One-way ANOVA analysis showing correlation between groups and within groups

\begin{tabular}{|c|c|c|c|c|c|c|}
\hline & & Sum of squares & $d f$ & Mean square & $\boldsymbol{F}$ & P-value* \\
\hline \multirow[t]{3}{*}{ Dopamine } & Between groups & $21,635.444$ & 5 & $4,327.089$ & 333.284 & 0.000 \\
\hline & Within groups & 947.772 & 73 & 12.983 & & \\
\hline & Total & $22,583.215$ & 78 & & & \\
\hline \multirow[t]{3}{*}{ DOPAC } & Between groups & 26.917 & 5 & 5.383 & 31.271 & 0.000 \\
\hline & Within groups & 12.567 & 73 & 0.172 & & \\
\hline & Total & 39.484 & 78 & & & \\
\hline \multirow[t]{3}{*}{ HVA } & Between groups & $|, 060.95|$ & 5 & 212.190 & 245.353 & 0.000 \\
\hline & Within groups & 63.133 & 73 & 0.865 & & \\
\hline & Total & I,I24.084 & 78 & & & \\
\hline \multirow[t]{3}{*}{ Serotonin } & Between groups & $140,676.456$ & 5 & $28,|35.29|$ & 245.065 & 0.000 \\
\hline & Within groups & $8,380.961$ & 73 & 114.808 & & \\
\hline & Total & $149,057.4 \mid 8$ & 78 & & & \\
\hline \multirow[t]{3}{*}{ HIAA } & Between groups & $21,429.77 \mid$ & 5 & $4,285.954$ & 91.032 & 0.000 \\
\hline & Within groups & $3,436.963$ & 73 & 47.082 & & \\
\hline & Total & $24,866.734$ & 78 & & & \\
\hline \multirow[t]{3}{*}{ Epinephrine } & Between groups & $1,879.219$ & 5 & 375.844 & 18.000 & 0.000 \\
\hline & Within groups & I,524.224 & 73 & 20.880 & & \\
\hline & Total & $3,403.443$ & 78 & & & \\
\hline \multirow[t]{3}{*}{ Norepinephrine } & Between groups & $24,655,933.049$ & 5 & $4,931,186.610$ & $1,061.419$ & 0.000 \\
\hline & Within groups & $339,146.419$ & 73 & 4,645.84I & & \\
\hline & Total & $24,995,079.468$ & 78 & & & \\
\hline
\end{tabular}

Note: $*$ The mean difference is significant at the $P<0.05$ level.

Abbreviations: ANOVA, analysis of variance; Sig, significance; DOPAC, 3,4-dihydroxyphenylacetic acid; HVA, homovanillic acid; HIAA, hydroxyindoleacetic acid.

Post hoc tests for all tested groups (multiple comparisons, Tukey's HSD) in Tables 3-5 show (Figure 1A) significant elevation in DA in all khat chewing groups, while SKch and SKcr groups are showing significant elevation in DA level than HKc group, exhibiting the significant positive effect of khat on DA increment in both SKch and SKcr groups. DOPAC (Figure 1B) is illustrating significant decrease in all khat chewing groups with an interesting outcome, the unexpected significant increase in SNKcr group. HVA is illustrating significant elevation in all khat chewing groups; SKch group is illustrating significant increase in HVA than SKcr group (Figure 1C).

Serotonin (Figure 2A) is illustrating significant elevation in all khat chewing groups with significant increase in both SKch and SKcr groups, and HIAA (Figure 2B) is illustrating significant elevation in all khat chewing groups with significant increase in SKch and SKcr groups.
Norepinephrine (Figure 3A) is illustrating significant elevation in all khat chewing groups with significant increase in both SKch and SKcr groups. Epinephrine (Figure 3B) is illustrating significant elevation in all chewers than non-chewers. Another interesting finding is encountered in the unexpected significant decrease in epinephrine in the SNKcr group, indicating that risperidone drug is possibly decreasing plasma epinephrine. Table 6 shows the improvement/deterioration in symptoms according to khat chewing within 12 weeks duration. Table 7 shows the sociodemographic and clinical characteristics.

\section{Discussion}

In vitro studies reported that cathinone may act on noradrenaline transporters and serotonin receptors and induce motor activities and was found to have four times higher affinity than racemic amphetamine for serotonin receptors in isolated rat fundus. ${ }^{24,30,31}$

Table 2 Multivariate tests

\begin{tabular}{lllllll}
\hline & Value & $\boldsymbol{F}$ & Hypothesis $\boldsymbol{d f}$ & Error df & P-value & Partial eta squared \\
\hline Pillai's trace & 2.566 & 10.696 & 35.000 & 355.000 & 0.000 & 0.513 \\
Wilks' lambda & 0.001 & 39.703 & 35.000 & 284.273 & 0.000 & 0.775 \\
Hotelling trace & 116.720 & 218.100 & 35.000 & 327.000 & 0.000 & 0.959 \\
Roy's largest root & 110.248 & $1,118.228$ & 7.000 & 71.000 & 0.000 & 0.991 \\
\hline
\end{tabular}

Notes: Each $F$ tests the multivariate effect of subject. These tests are based on the linearly independent pairwise comparisons among the estimated marginal means. Abbreviation: Sig, significance. 
Table 3 Effects of khat chewing and paranoid schizophrenia on plasma levels of dopamine and its related metabolites (DOPAC and HVA), in comparison with healthy non-khat-chewer subjects

\begin{tabular}{|c|c|c|c|c|c|c|}
\hline \multirow[t]{3}{*}{ Variables } & \multicolumn{2}{|c|}{ Healthy subjects $(n=37)$} & \multicolumn{4}{|c|}{ Schizophrenic subjects $(n=42)$} \\
\hline & \multirow{2}{*}{$\begin{array}{l}\text { HNKc } \\
(n=20)\end{array}$} & \multirow{2}{*}{$\begin{array}{l}\text { HKc } \\
(n=17)\end{array}$} & \multicolumn{2}{|l|}{ SNKc $(n=2 I)$} & \multicolumn{2}{|l|}{ SKc $(n=2 I)$} \\
\hline & & & $\begin{array}{l}\text { SNKch (10 mg/day) } \\
(n=10)\end{array}$ & $\begin{array}{l}\text { SNKcr (5 mg/day) } \\
(\mathrm{n}=\mathrm{II})\end{array}$ & $\begin{array}{l}\text { SKch (10 mg/day) } \\
(\mathrm{n}=10)\end{array}$ & $\begin{array}{l}\text { SKcr (5 mg/day) } \\
(n=I I)\end{array}$ \\
\hline Dopamine (pg/mL) & $24.30 \pm 0.63$ & $50.5 \pm 1.24 * * *$ & $23.2 \pm 1.11$ & $19.82 \pm 0.48^{\top}$ & $61.3 \pm 1.25 * * *, 000$ & $57.0 \pm 0.93 * * *, 000$ \\
\hline DOPAC (ng/mL) & $3.0 \pm 0.10$ & $2.46 \pm 0.15 * *$ & $2.03 \pm 0.05 \nabla \nabla \nabla$ & $2.97 \pm 0.07$ & $1.48 \pm 0.05^{*, 000}$ & $1.65 \pm 0.08 * * * *, 000$ \\
\hline HVA (ng/mL) & $9.29 \pm 0.17$ & $|2.56 \pm 0.3| * * *$ & $10.05 \pm 0.39$ & $9.72 \pm 0.10$ & $19.25 \pm 0.23 * * *, 000$ & $17.3 \pm 0.19 * * *, 000$ \\
\hline
\end{tabular}

Notes: Each value represents as mean \pm SEM. *For comparison between khat-chewers and non-chewers between groups and within groups, $\mathbf{v}$ for comparison between $\mathrm{SNKch}$ or $\mathrm{SNKcr}$ and $\mathrm{HNKc}$, and ${ }^{\circ}$ for comparison between $\mathrm{SKch}$ or $\mathrm{SKcr}$ and HKc. Note that mostly rest of all other comparisons were significant. $*, \mathbf{v}<<0.05$; $* * P<0.0 \mathrm{I}$; $* * *, \nabla \vee \nabla, 000 \mathrm{P}<0.001$

Abbreviations: S, schizophrenic; K, khat; c, chewing; N, non; r, risperidone; h, haloperidol; DOPAC, 3,4-dihydroxyphenylacetic acid; HVA, homovanillic acid; SEM, standard error of the mean.

Repeated doses of amphetamines $5 \mathrm{mg} / \mathrm{kg}$ twice daily for successive 5 days in rats induce behavioral sensitization phenomenon due to DA release..$^{32,33}$

In addition, administration of khat or cathinone to rats after unilateral lesion of substantia nigra with 6-hydroxydopamine induced ipsilateral rotation, in a similar fashion to amphetamine, suggesting that they have indirect DA-releasing actions on the CNS. ${ }^{34}$

Several preclinical studies on rats treated with cathinone $(3.2 \mathrm{mg} / \mathrm{kg}$ ) showed increase in DA efflux measured by microdialysis (55\%), and the behavioral effect of cathinone in animals is attributed to increasing the level of DA release or inhibiting its reuptake, ${ }^{12,35,36}$ and this might explain the khatinducing behavioral sensitization phenomenon. Locomotor sensitization and deficits in prepulse inhibition induced by psychostimulants are two paradigms that have been widely studied as animal behavioral models of amphetamine psychosis. Repeated oral administration of a standardized C. edulis extract (containing a dose of $1 \mathrm{mg}$ cathinone per kilogram body weight) or (-) cathinone $(1.5 \mathrm{mg} / \mathrm{kg})$ to rats induced a strong locomotor sensitization and led to a gradual deficit in prepulse inhibition. ${ }^{4}$
Chronic administration of either the whole khat extract or cathinone in rats results in a significant depletion of DA in several brain areas, particularly on the nigrostriatal DA terminal projections, ${ }^{4}$ and exhibits the same neurotoxic effect of chronic amphetamine administration on the dopaminergic innervations of caudate, inducing their degeneration. ${ }^{37}$

Cathinone has to penetrate to intraneuronal sites in order to evoke release, and the uptake inhibitors prevent this penetration; therefore, DA release inhibitors or pretreatment with the relatively selective dopaminergic neurotoxin 6-hydroxydopamine significantly attenuates cathinoneinduced effects, ${ }^{25,32}$ while Zelger et al ${ }^{38}$ have demonstrated that pretreatment with reserpine (monoamine store depleting agent) or methyl- $p$-tyrosine (a catecholamine synthesis inhibitor) abolished locomotor and increased stereotyped behavior induced by cathinone. On the other hand, pretreatment with haloperidol, a non-selective DA antagonist, was found to reduce biting and licking movements caused by cathinone.

In vivo microdialysis in rats after acute intraperitoneal administration of cathinone, in a similar fashion to amphetamine, increased levels of DA but decreased levels

Table 4 Effects of khat chewing and paranoid schizophrenia on plasma levels of serotonin (5-HT) and its metabolite (HIAA), in comparison with healthy non-khat-chewer subjects

\begin{tabular}{|c|c|c|c|c|c|c|}
\hline \multirow[t]{3}{*}{ Variables } & \multicolumn{2}{|c|}{ Healthy subjects $(n=37)$} & \multicolumn{4}{|c|}{ Schizophrenic subjects $(n=42)$} \\
\hline & \multirow{2}{*}{$\begin{array}{l}\text { HNKc } \\
(n=20)\end{array}$} & \multirow{2}{*}{$\begin{array}{l}\text { HKc } \\
(n=17)\end{array}$} & \multicolumn{2}{|l|}{ SNKc $(n=21)$} & \multicolumn{2}{|l|}{$\operatorname{SKc}(n=2 I)$} \\
\hline & & & $\begin{array}{l}\text { SNKch (10 mg/day) } \\
(n=10)\end{array}$ & $\begin{array}{l}\text { SNKcr (5 mg/day }) \\
(n=I I)\end{array}$ & $\begin{array}{l}\text { SKch }(10 \mathrm{mg} / \text { day }) \\
(\mathrm{n}=10)\end{array}$ & $\begin{array}{l}\text { SKcr (5 mg/day) } \\
(n=I I)\end{array}$ \\
\hline Serotonin $(5-\mathrm{HT})(\mathrm{ng} / \mathrm{mL})$ & $199.40 \pm 2.78$ & $262.18 \pm 2.05^{* * *}$ & $221.3 \pm 1.89 \vee v \nabla$ & $206.36 \pm 3.16$ & $309.5 \pm 5.03 * * *, 000$ & $297.6 \pm 2.27 * * *, 000$ \\
\hline 5-HIAA (nmol/L) & $58.10 \pm 1.18$ & $85.41 \pm 1.62^{* * *}$ & $64.3 \pm 4.19$ & $59.09 \pm 1.42$ & $99.6 \pm 1.8 * * *, 000$ & $93.82 \pm 0.93 * * *, 0$ \\
\hline
\end{tabular}

Notes: Each value represents as mean \pm SEM. *For comparison between khat-chewers and non-chewers between groups and within groups, $\mathbf{V}$ for comparison between SNKch or SNKcr and HNKc, and ${ }^{\circ}$ for comparison between SKch or SKcr and HKc. Note that mostly rest of all other comparisons were significant. ${ }^{\circledR} \mathrm{P}<0.05$; $* * *, \nabla \nabla \nabla, 000 \mathrm{P}<0.001$.

Abbreviations: 5-HT, 5-hydroxytryptamine; HIAA, hydroxyindoleacetic acid; S, schizophrenic; K, khat; c, chewing; N, non; r, risperidone; h, haloperidol; SEM, standard error of the mean. 
Table 5 Effects of khat chewing and paranoid schizophrenia on plasma levels of norepinephrine and epinephrine, in comparison with healthy non-khat-chewer subjects

\begin{tabular}{|c|c|c|c|c|c|c|}
\hline \multirow[t]{3}{*}{ Variables } & \multicolumn{2}{|c|}{ Healthy subjects $(n=37)$} & \multicolumn{4}{|c|}{ Schizophrenic subjects $(n=42)$} \\
\hline & \multirow{2}{*}{$\begin{array}{l}\text { HNKc } \\
(n=20)\end{array}$} & \multirow{2}{*}{$\begin{array}{l}\text { HKc } \\
(n=I 7)\end{array}$} & \multicolumn{2}{|l|}{ SNKc $(n=2 I)$} & \multicolumn{2}{|l|}{$\operatorname{SKc}(n=2 I)$} \\
\hline & & & $\begin{array}{l}\text { SNKch (10 mg/day) } \\
(n=10)\end{array}$ & $\begin{array}{l}\text { SNKcr (5 mg/day }) \\
(\mathrm{n}=\mathrm{II})\end{array}$ & $\begin{array}{l}\text { SKch (10 mg/day) } \\
(\mathrm{n}=10)\end{array}$ & $\begin{array}{l}\text { SKcr (5 mg/day) } \\
(n=I I)\end{array}$ \\
\hline Norepinephrine (pg/mL) & $863.70 \pm 7.28$ & $1,902.88 \pm 26.31 * * *$ & $906.5 \pm 6.5$ & $889.45 \pm 2.96$ & $2,092.5 \pm 34.4 * * *, 000$ & $2,041.45 \pm 13.3 * * *, 000$ \\
\hline Epinephrine (pg/mL) & $108.95 \pm 1.42$ & $115.12 \pm 1.23 * *$ & $111.3 \pm 1.07$ & $102.72 \pm 1.13^{\mathrm{V}}$ & $119.5 \pm 0.72 * *$ & $113.45 \pm 0.64^{* * * *}$ \\
\hline
\end{tabular}

Notes: Each value represents as mean \pm SEM. *For comparison between khat-chewers and non-chewers between groups and within groups, ' for comparison between SNKch or SNKcr and HNKc, and ${ }^{\circ}$ for comparison between SKch or SKcr and HKc. Note that mostly rest of all other comparisons were significant. $* *, \nabla \nabla P<0.0 \mathrm{I}$; $* * *, 000 \mathrm{P}<0.00 \mathrm{I}$. Abbreviations: S, schizophrenic; K, khat; c, chewing; N, non; r, risperidone; h, haloperidol; SEM, standard error of the mean.

\section{Bars show means}

\section{Error bars show mean $\pm 1.0 \mathrm{SE}$}

A

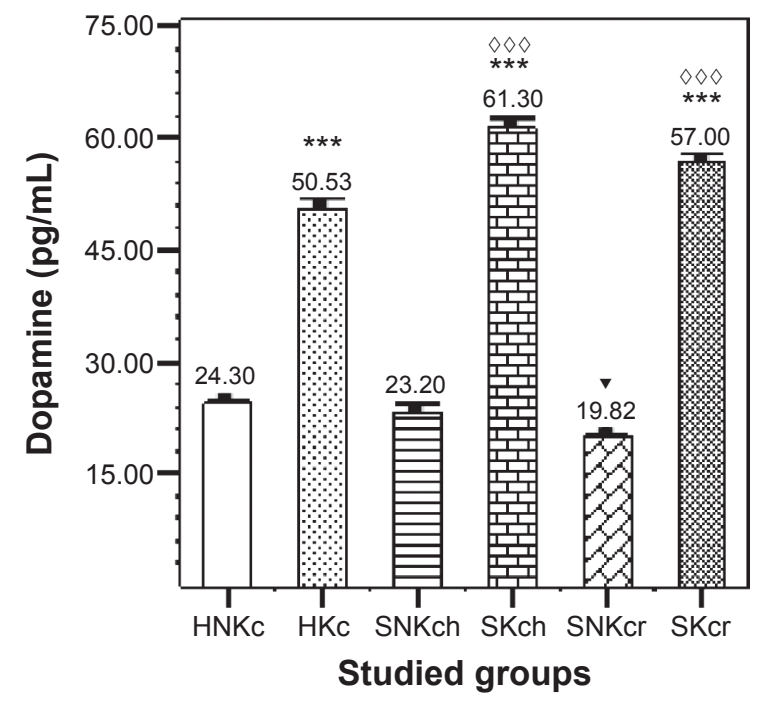

B

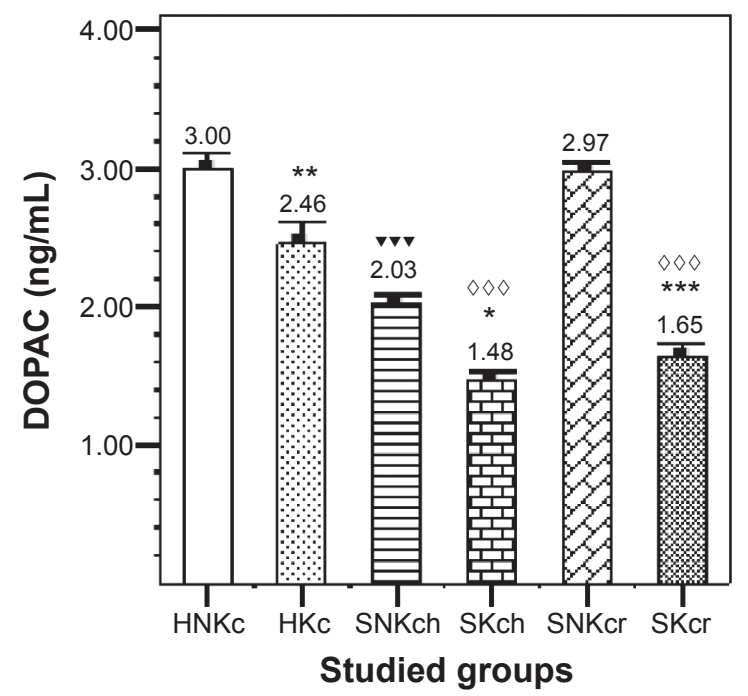

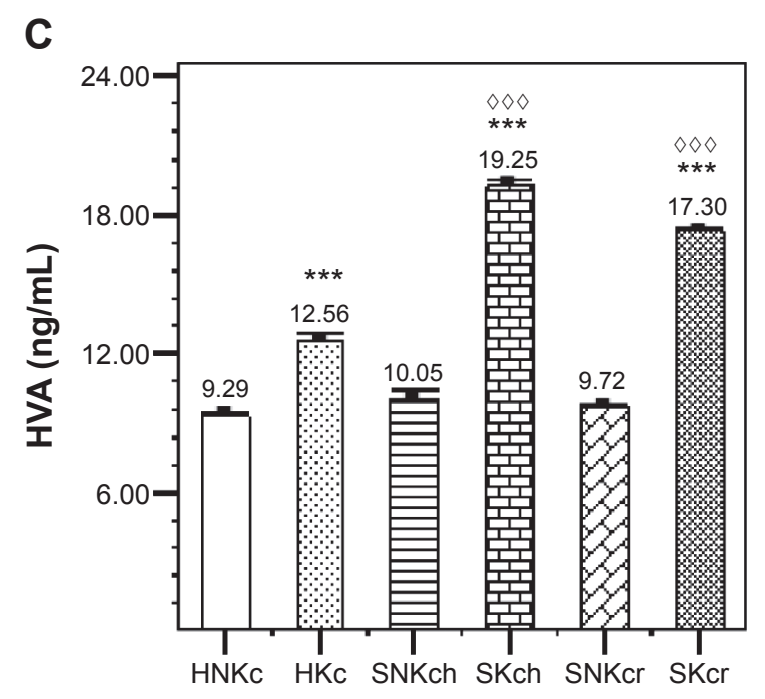

Studied groups

Figure I Effects of khat chewing and paranoid schizophrenia on plasma level of dopamine (A) and its related metabolites, DOPAC (B) and HVA (C).

Notes: Each value represents as mean \pm SEM. *For comparison between khat-chewers and non-chewers between groups and within groups, $\mathbf{v}$ for comparison between $\mathrm{SNK}$ ch or SNKcr and HNKc, and ${ }^{\circ}$ for comparison between SKch or SKcr and HKc. Note that mostly rest of all other comparisons were significant. $*, \mathbf{v} P<0.05$; $* * P<0.0 \mathrm{I}$; $* * *, \nabla \nabla, 000 \mathrm{P}<0.001$.

Abbreviations: H, healthy; N, non; K, khat; c, chewing; S, schizophrenic; h, haloperidol; r, risperidone; DOPAC, 3,4-dihydroxyphenylacetic acid; HVA, homovanillic acid; SE, standard error; SEM, standard error of the mean. 


\section{Bars show means}

\section{Error bars show mean $\pm 1.0 \mathrm{SE}$}

A

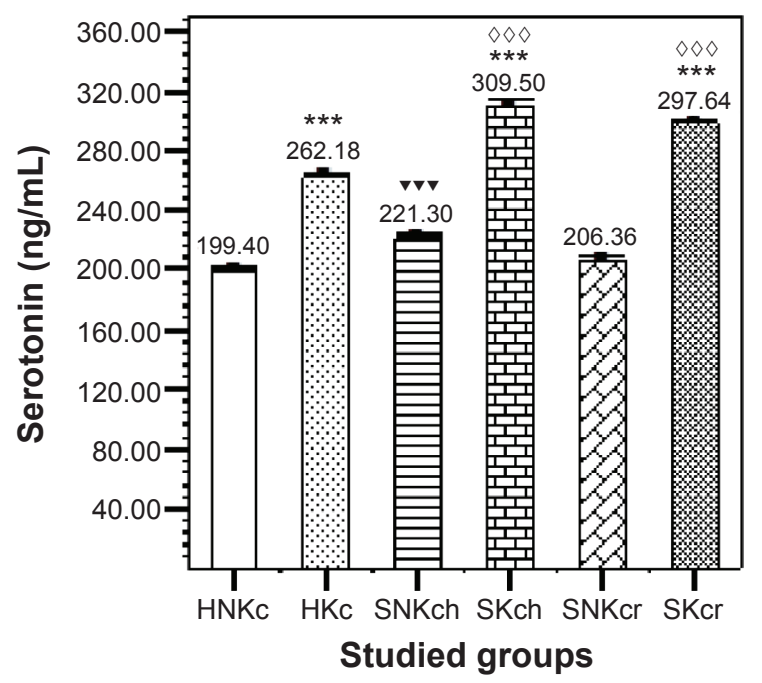

B

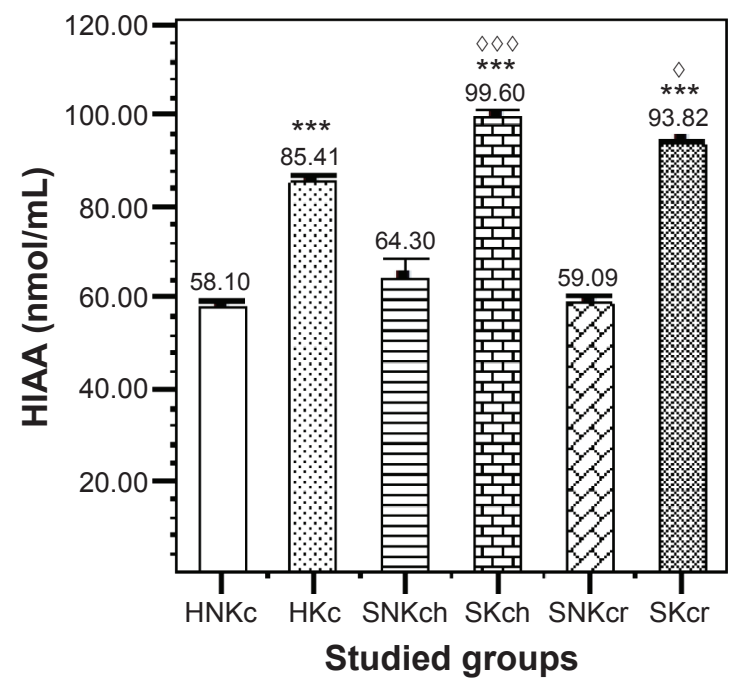

Figure 2 Effects of khat chewing and paranoid schizophrenia on plasma level of serotonin (A) and its related metabolite HIAA (B).

Notes: Each value represents as mean \pm SEM. *For comparison between khat-chewers and non-chewers between groups and within groups, $\mathbf{f}$ for comparison between SNKch or SNKcr and HNKc, and ${ }^{\circ}$ for comparison between SKch or SKcr and HKc. Note that mostly rest of all other comparisons were significant. ${ }^{\ominus} \mathrm{P}<0.05$; ${ }^{*} * *, \nabla \nabla \nabla, 000 \mathrm{P}<0.00 \mathrm{I}$. Abbreviations: H, healthy; N, non; K, khat; c, chewing; S, schizophrenic; h, haloperidol; r, risperidone; HIAA, hydroxyindoleacetic acid; SE, standard error; SEM, standard error of the mean.

of DA metabolite DOPAC in a dose-dependent manner, ${ }^{19}$ and similar to amphetamine, cathinone led to depletion of serotonin and its corresponding metabolites in both anterior and posterior striatum, which suggests that aggression in this paradigm is enhanced presumably by decreasing the level of serotonin and its metabolites. ${ }^{34}$
In human, khat induces hypomanic illness with grandiose delusions and paranoid or schizophrenic psychosis with persecutory delusions associated with mainly auditory hallucinations, fear, and anxiety, resembling amphetamine psychosis, ${ }^{21,39}$ and induced psychotic states have been described in over 20 case reports, ${ }^{40}$ while recent community-based stud-

\section{Bars show means}

\section{Error bars show mean $\pm 1.0 \mathrm{SE}$}

A

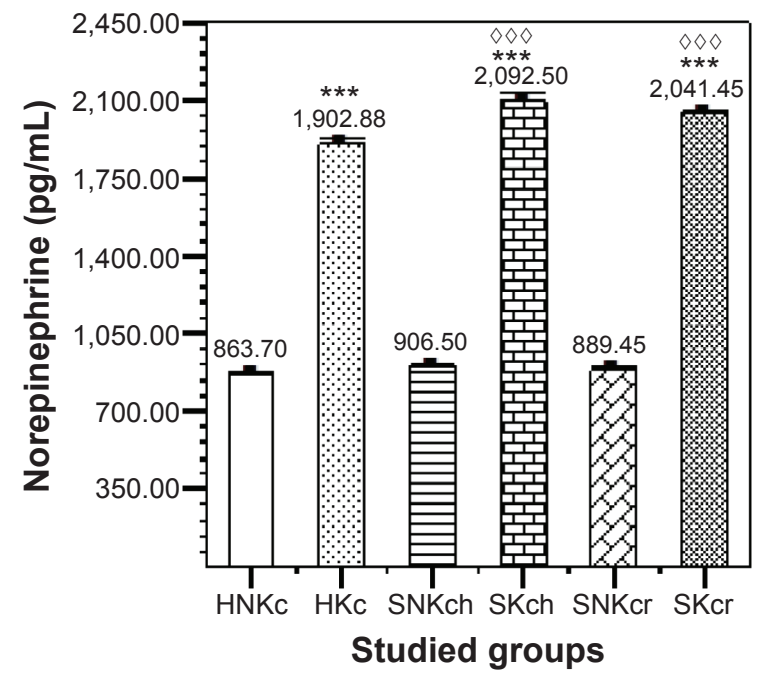

B

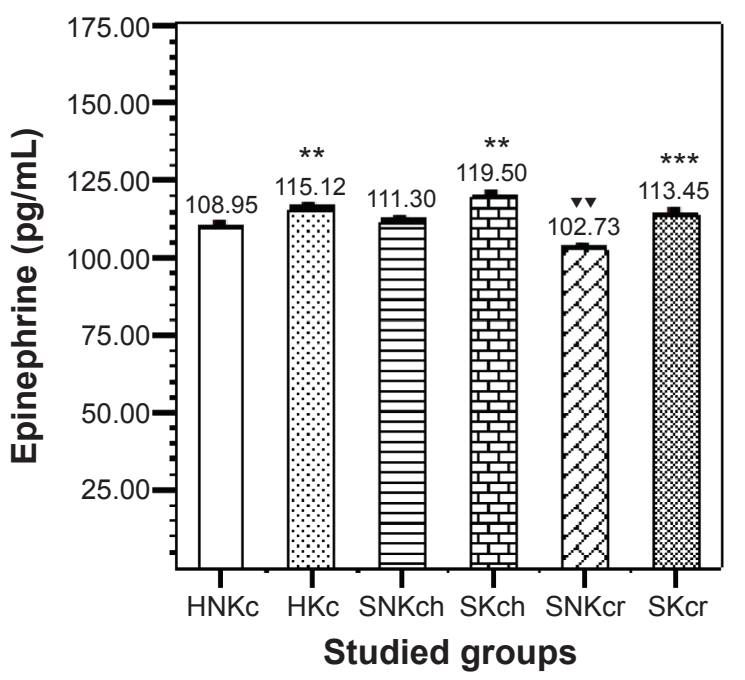

Figure 3 Effects of Khat chewing and paranoid schizophrenia on plasma level of norepinephrine (A), and epinephrine (B).

Notes: Each value represents as mean \pm SEM. *For comparison between khat-chewers and non-chewers between groups and within groups, 'for comparison between SNKch or SNKcr and HNKc, and ${ }^{\circ}$ for comparison between SKch or SKcr and HKc. Note that mostly rest of all other comparisons were significant. $* *, \mathbf{v} P<0.0 \mathrm{I}$; $* * *, 000 \mathrm{P}<0.00 \mathrm{I}$. Abbreviations: $\mathrm{H}$, healthy; $\mathrm{N}$, non; K, khat; c, chewing; S, schizophrenic; h, haloperidol; r, risperidone; SE, standard error; SEM, standard error of the mean. 

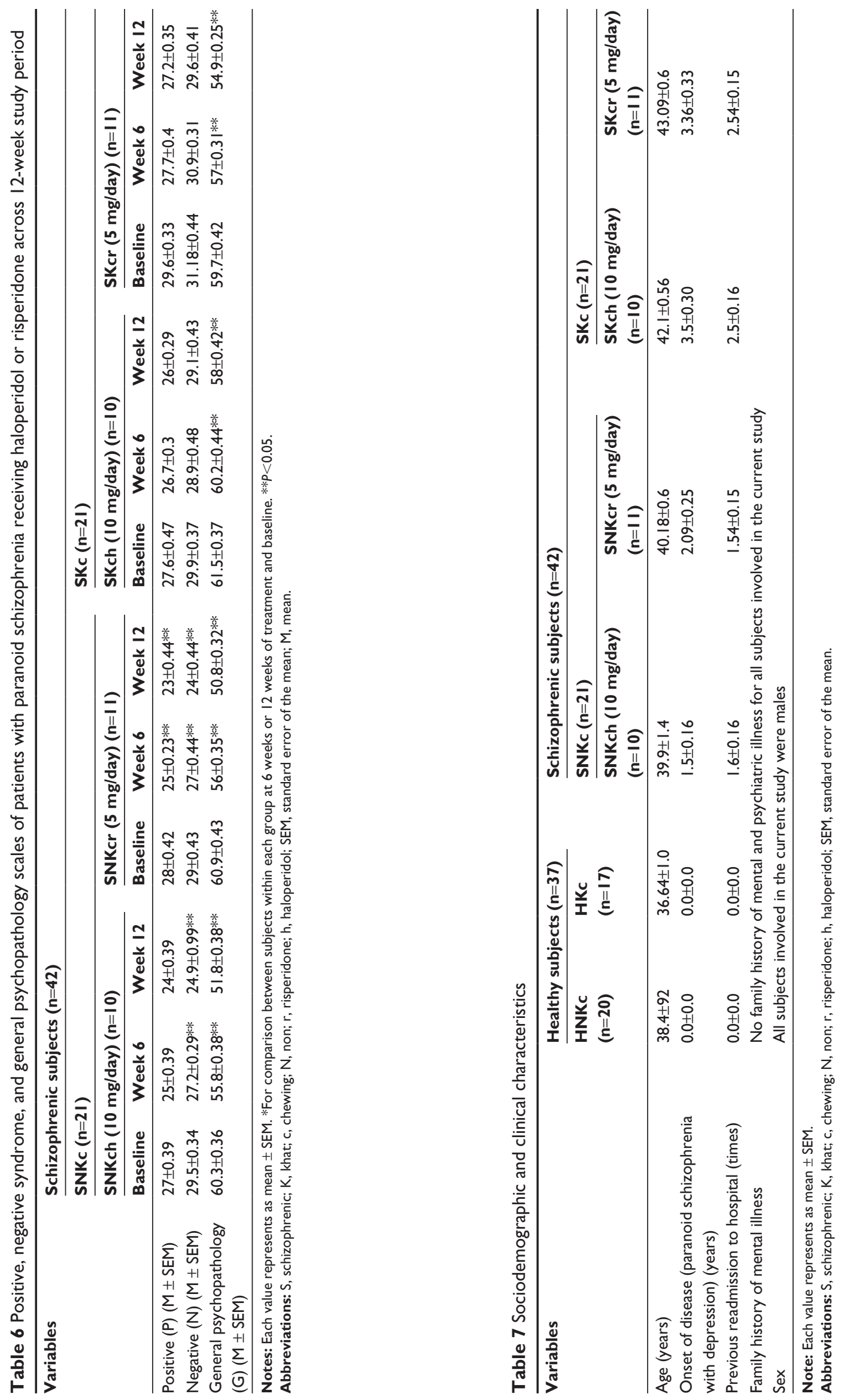
ies showed that khat use is associated with severe psychiatric problems. ${ }^{41}$

There are a number of reports of psychiatric disorders secondary to khat chewing with features of manic-like psychosis $^{6}$ and paranoid psychosis. ${ }^{7,8}$

Accordingly, two cases of homicide and combined homicide and suicide have been reported following consumption of khat. ${ }^{7,39}$

In addition to cathinone, other khat cathine alkaloid or d-norpseudoephedrine has been identified as an additional psychoactive ingredient with psychostimulant properties. ${ }^{42}$

Khat withdrawal syndrome includes dysphoria, depression, irritability, anxiety, poor concentration, hypersomnia, fatigue, paranoia, akathisia, and drug craving. ${ }^{43,44}$

Several investigators claim that khat use is not necessarily linked to psychological morbidity; any association that is found may reflect an interaction with other environmental factors. ${ }^{10}$

This study's results come in agreement with all the previous studies, as schizophrenic patients khat chewing groups (SKch and SKcr) for treated patients showed significant increase in DA, DA metabolite HVA, serotonin, serotonin metabolites HIAA, epinephrine, and norepinephrine than schizophrenic patients non-khat chewing groups (SNKch and SNKcr) and control healthy groups (HNKc and HKc). This outcome was explained by khat induction release effect on both DA and serotonin through khat cathinone and cathine alkaloids.

This study revealed two interesting outcomes. The first one was the significant increase in DOPAC in the SNKcr group and was expected to show the same decrement pattern like other non-khat-chewer group, SNKch, and this outcome could be explained as risperidone treatment induced a decrement in plasma DA levels and increment in plasma DOPAC in the schizophrenic patients. ${ }^{45}$ Khat chewing in the SKcr group had compensated the induction effect of risperidone, and the DOPAC plasma level was declined. This might deeply explain the mechanism of action for risperidone through affecting DA biosynthesis and metabolism.

The second interesting outcome was the marked significant decrease in epinephrine in the SNKcr group than other groups, particularly SNKch and HNKc groups, and this could be explained as serotonin concentration dependent can increase $\mathrm{Ca}^{2+}$ and its effect is blocked by a broad-spectrum 5-HT antagonist (metergoline). Calcium triggers the exocytosis of chromaffin granules, releasing epinephrine into the bloodstream. ${ }^{46-48}$ Risperidone is a 5-HT antagonist; therefore, it blocks $\mathrm{Ca}^{2+}$ elevation by serotonin and consequently blocks release of epinephrine into the bloodstream.
According to PANSS scores assessed at study startup, after 6 weeks, and then after 12 weeks duration (Table 6), khat chewing prohibited the improvements in SKcr PANSS positive and PANSS negative and significantly deteriorated the PANSS general scale.

This study showed two limitations: we could not confirm the khat effect on SKch PANSS positive because the SNKch group showed non-significant mild improvement and the other limitation is the discontinuation of khat administration during hospitalization periods.

In conclusion, khat chewing in schizophrenic patients is contraindicated because it aggravates the disease symptoms, attenuates all used treatment medications, and deteriorates all biochemical markers of the patients.

\section{Acknowledgment}

We would like to express our gratitude to medical staff of Al-Amal Hospital for their cooperation during the study.

\section{Author contributions}

Both authors were involved and contributed to the proposal design, conception, and design of the manuscript; analyzed, collected, assembled, and interpreted the data; provided the study material, intellectual content, and graphics design; and were involved in manuscript writing and the final approval of the manuscript.

\section{Disclosure}

We declare no conflict of interests with any other party. This study was completely covered financially by the authors, and no grants or funds by any type either governmental or industrial were received.

\section{References}

1. Davis K, Kahn RS, Ko G, Davidson M. Dopamine in schizophrenia: a review and reconceptualization. Am J Psychiatry. 1991;148:1474-1486.

2. Souhel N, Daniel MP. Neuroinflammation and white matter pathology in schizophrenia: systematic review. Schizophr Res. 2015;161(1):102-112.

3. Najjar S, Pearlman DM, Alper K, Najjar A, Devinsky O. Neuroinflammation and psychiatric illness. J Neuroinflammation. 2013;10:43.

4. Banjaw M, Schmidt W. Behavioural sensitization following repeated intermittent oral administration of Catha edulis in rats. Behav Brain Res. 2005;156:181-189.

5. Balint E, Falkay G, Balint G. Khat-a controversial plant. Middle Eur J Med. 2009;121:604-614.

6. Gough SP, Cookson IB. Khat induced schizophreniform psychosis in UK (letter). Lancet. 1984;i:455.

7. Alem A, Shibre T. Khat induced psychosis and its medico-legal implication: a case report. Ethiop Med J. 1997;35:137-139.

8. Nielen RJ, van der Heijden FM, Tuiner S, Verhoeven WM. Khat and mushrooms associated with psychosis. World J Biol Psychiatry. 2004;5:49-53.

9. Al Habori M. The potential adverse effects of habitual use of Catha edulis (khat). Expert Opin Drug Saf. 2005;4:1145-1154. 
10. Odenwald M, Neuner F, Schauer M, et al. Khat use as risk factor for psychotic disorders: a cross-sectional and case-control study in Somalia. BMC Med. 2005;3:5-15.

11. Schechter M, Meehan SM. Conditioned place preference produced by the psychostimulant cathinone. Eur J Pharmacol. 1993;232:135-138.

12. Al-Hebshi N, Skaug N. Khat (Catha edulis) - an updated review. Addict Biol. 2005;10:299-307.

13. Dani JA, Zhou FM. Selective dopamine filters of glutamate striatal afferents. Neuron. 2004;42:522-524.

14. Baumgarten HG, Grozdanovic Z. Psychopharmacology of central serotonergic systems. Pharmacopsychiatry. 1995;2:73-79.

15. Kandel ER, Schwartz JH, Jessell TM. Principle of Neuronal Science. 4th ed. New York: McGraw-Hill/Appleton \& Lange Companies, Inc.; 2000.

16. Calcagnetti DJ, Schechter MD. Place preference for the psychostimulantcathinone is blocked by pretreatment with a dopamine release inhibitor. Prog Neuropsychopharmacol Biol Psychiatry. 1993;17:637-649.

17. Meltzer HY, Li Z, Kaneda Y, Ichikawa J. Serotonin receptors: their key role in drugs to treat schizophrenia. Prog Neuropsychopharmacol Biol Psychiatry. 2003;27:1159-1172.

18. Nencini P, Ahmed AM, Amiconi G, Elmi AS. Tolerance develops to sympathetic effects of khat in humans. Pharmacology. 1984;28:150-154.

19. Pehek EA, Schechter MD, Yamamoto BK. Effects of cathinone and amphetamine on the neurochemistry of dopamine in vivo. Neuropharmacology. 1990;29:1171-1176.

20. Kalix P. The pharmacology of khat. Gen Pharmacol. 1984;15:179-187.

21. Kalix P. The pharmacology of psychoactive alkaloids from Ephedra and Catha. J Ethnopharmacol. 1991;32:201-208.

22. Feyissa AM, Kelly JP. A review of the neuropharmacological properties of khat. Prog Neuropsychopharmacol Biol Psychiatry. 2008; 32:1147-1166.

23. Kotb El-Sayed MI, Amin HA. Effect of Catha edulis on insulin, resistin and cortisol levels in type-2 diabetics and non-diabetics. Am J Biochem Biotechnol. 2012;8:157-163.

24. Rothman RB, Roth BL, Hufeisen SJ, et al. In vitro characterization of ephedrine-related stereoisomer at biogenic amine transporters and the receptors revealed selective actions as norepinephrine transporter substrates. J Pharmacol Exp Ther. 2003;307:138-145.

25. Banjaw M, Schmidt W. Catha edulis extract and its active principle cathinone induce ipsilateral rotation in unilaterally lesioned rats. Behav Pharmacol. 2006; 17:615-620.

26. Schotte A, Janssen PF, Megens AA, Leysen JE. Occupancy of central neurotransmitter receptors by risperidone, clozapine and haloperidol, measured ex vivo by quantitative autoradiography. Brain Res. 1993;631:191-202.

27. Kay SR, Fiszbein A, Opler LA. The positive and negative syndrome scale (PANSS) for schizophrenia. Schizophr Bull. 1987;13:261-276.

28. World Health Organization. The ICD-10 Classification of Mental and Behavioral Disorders-Diagnostic Criteria for Research. Geneva: WHO; 2010.

29. Dethy S, Laute MA, Van Blercom N, Damhaut P, Goldman S, Hildebrand J. Microdialysis-HPLC for plasma levodopa and metabolites monitoring in parkinsonian patients. Clin Chem. 1997;43(5):740-744.

30. Glennon RA, Liebowitz SM. Serotonin receptor affinity of cathinone and related analogues. J Med Chem. 1982;25:393-397.
31. Calcagnetti DJ, Schechter MD. Increase locomotor activity of rat after intracerebral administration of cathinone. Brain Res Bull. 1992; 29:843-846.

32. Robinson TE, Becker JB. Enduring changes in brain and behavior produced by chronic amphetamine administration: a review and evaluation of animal models of amphetamine psychosis. Brain Res Rev. 1986;11:157-198.

33. Kalivas P. Neurotransmitter regulation of dopamine neurons in the ventral tegmental area. Brain Res Brain Res Rev. 1993;18:75-113.

34. Banjaw MY, Miczek K, Schmidt WJ. Repeated Catha edulis oral administration enhances the baseline aggressive behaviour in isolated rats. J Neural Transm. 2006;113:543-556.

35. Krause KH, Dresel SH, Krauser J, Kung HF, Tatsch K. Increased striatal dopamine transporter in adult patients with attention deficit hyperactive disorder: effects of methylphenidate as measured by single photon emission computed tomography. Neurosci Lett. 2000;285:107-110.

36. Kehr J, Ichinose F, Yoshitake S, et al. Mephedrone, compared with MDMA (ecstasy) and amphetamine, rapidly increases both dopamine and 5-HT levels in nucleus accumbens of awake rats. Br J Pharmacol. 2011;164:1949-1958.

37. Ellison G. Neural degeneration following chronic stimulant abuse reveals a weak link in brain, fasciculus retroflexus, implying the loss of forebrain control circuitry. Eur Neuropsychopharmacol. 2002; 12:287-297.

38. Zelger J, Schorno H, Carlin E. Behavioural effects of cathinone: an amphetamine obtained from Catha edulis: comparisons with amphetamine, norpseudoephedrine, apomorphine and nomifensine. Bull Narc. 1980;32:67-81.

39. Pantelis C, Hindler C, Taylor J. Use and abuse of khat (Catha edulis): a review of the distribution, pharmacology, side effects and a description of psychosis attributed to khat chewing. Psychol Med. 1989;19:657-668.

40. Warfa N, Klein A, Bhui K, Leavey G, Craig T, Stansfeld S. Khat use and mental illness: a critical review. Soc Sci Med. 2007;65:309-318.

41. Bhui K, Craig T, Mohamud S, Warfa N, Stansfeld SA, Thornicroft G. Mental disorders among Somali refugees developing culturally appropriate measures and assessing socio-cultural risk factors. Soc Psychiatry Psychiatr Epidemiol. 2006;41:400-408.

42. Graziani M, Milella M, Nencini P. Khat chewing from the pharmacological point of view: an update. Subst Use Misuse. 2008;43:762-783.

43. Barr A, Markou A, Phillips AA. 'crash' course on psychostimulant withdrawal as a model of depression. Trends Pharmacol Sci. 2002; 23:475-482.

44. Zweben J, Cohen J, Christian D, et al. Psychiatric symptoms in methamphetamine users. Am J Addict. 2004;13:181-190.

45. Cai HL, Fang P, Li HD, et al. Abnormal plasma monoamine metabolism in schizophrenia and its correlation with clinical responses to risperidone treatment. Psychiatry Res. 2011;188:197-202.

46. Bennett MR. One hundred years of adrenaline: the discovery of autoreceptors. Clin Auton Res. 1999;9:145-159.

47. Flett J, Colwell C. Serotonin modulation of calcium transients in cells in the suprachiasmatic nucleus. J Biol Rhythms. 1999;14:354-363.

48. Aronson J. Where name and image meet" - the argument for "adrenaline. Br Med J. 2000;320:506-509.
Neuropsychiatric Disease and Treatment

\section{Publish your work in this journal}

Neuropsychiatric Disease and Treatment is an international, peerreviewed journal of clinical therapeutics and pharmacology focusing on concise rapid reporting of clinical or pre-clinical studies on a range of neuropsychiatric and neurological disorders. This journal is indexed on PubMed Central, the 'PsycINFO' database and CAS,
Dovepress

and is the official journal of The International Neuropsychiatric Association (INA). The manuscript management system is completely online and includes a very quick and fair peer-review system, which is all easy to use. Visit http://www.dovepress.com/testimonials.php to read real quotes from published authors. 